Le Devoir, Montréal, Édition du 28 août 1998.

\title{
Une suite logique de l'ALENA
}

\section{Le Canada doit abandonner le dollar canadien}

\section{En attendant une unité monétaire mondiale, le Canada devrait se lier complètement à la monnaie américaine}

\section{Bernard Élie}

Professeur au Département des sciences économiques, Université du Québec à Montréal

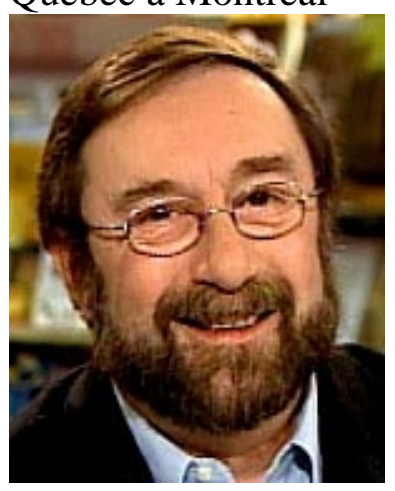

La croissance du volume mondial des échanges en biens et services et leur grande importance dans les économies nationales (depuis dix ans les exportations du Canada ont bondi de $20 \%$ à $40 \%$ du PIB), accompagnée de l'hyperdéveloppment des marchés financiers, fondent les conditions de la disparition des monnaies nationales.

Les dizaines de milliers de milliards de dollars, sur des marchés financiers extrêmement volatiles, peuvent facilement entraîner des fluctuations des taux de change que les autorités monétaires n'ont plus les moyens de contrôler. La crise asiatique provoqua un flux de capitaux vers les avoirs libellés en dollars américains (la valeur refuge) qui amena une hausse de dollar américain par rapport à toutes les monnaies. Le dollar canadien, très sensible à la demande et aux prix des matières premières, décrocha encore plus face à la devise américaine. Que faire ? Tous s'entendent pour dire que notre douar est sous-évalué. Artificiellement, les industries exportatrices du Canada semblent être favorisées à court terme. Mais ses gains de compétitivité seront rapidement annulés par la croissance des prix des biens d'équipement que nous importons largement. L'inflation à terme sera néfaste pour tous les Canadiens.

Le laissez-faire, ou l'abandon aux marchés, est inacceptable car l'incertitude et ses coûts seront trop élevés. Les interventions de la Banque du Canada sauront-elles arrêter la chute de notre monnaie et la ramener à un niveau souhaitable face au dollar américain ? Ce niveau non 
inflationniste à atteindre, quel est-il ? Entre 0,70 et $0,85 \$$ US !

Ce taux de change sera-t-il fixe ? Cette hypothèse suppose que la Banque du Canada puisse contraindre les mouvements des marchés en fonction de la cible choisie. Aucun pays, même avec l'aide du FMI, n'a les moyens d'une telle politique aujourd'hui. Le Canada doit se rattacher à une autre unité de compte et abandonner le dollar canadien.

\section{L'exemple européen}

Les Européens ont adopté une nouvelle unité de compte, l'euro. Finis franc, mark, schilling, couronne, peseta, lire, escudo et florin. D'un coup, la plus grande partie de leurs transactions internationales sera à l'abri de toute fluctuation des taux de change $(80 \%$ des opérations internationales des membres de l'Europe monétaire se font entre eux). Les exportations du Canada sont dirigées essentiellement vers les États-Unis (à $81 \%$ ) et nos importations proviennent principalement de chez nos voisins (à 76\%). Notre intégration, surtout depuis le traité de libreéchange de 1987, est de plus en plus forte. En attendant une unité monétaire mondiale, le Canada devra se lier complètement à la monnaie américaine en adoptant son dollar comme unité de compte. Oublions la relative autonomie de nos politiques monétaires. Mais, si nous y regardons bien, il ne s'agit que de la suite logique de l'ALENA
D'ici quelques semaines, des titres canadiens libellés en dollars canadiens seront à échéance, pour plus de 50 milliards. Que feront les investisseurs de ces dollars canadiens? Acheter de nouvelles émissions de titres en dollars canadiens, l'économie canadienne étant fondamentalement saine ? Peut-être y aura-t-il une demande, mais où sera l'offre des titres? Les gouvernements ont réduit leurs besoins de financement, lutte contre le déficit oblige, et les entreprises canadiennes n'ont pas pris la relève à la même hauteur. Notre monnaie n'étant pas très utilisée de par le monde, où iront ces dollars canadiens ainsi libérés ? Vers des actifs libellés en dollars américains. Les tourments de notre dollars reprendront. La mondialisation, au sens de la croissance des volumes des échanges et des flux de capitaux, conduit à rendre impossible l'administration des petites monnaies.

Dans le contexte économique et politique qui est le nôtre, nous ne pouvons envisager la mise en place d'un système monétaire semblable à celui de l'Europe avec l'euro. Pas question d'un americano ; il ne nous reste alors que la soumission au dollar. À long terme, espérons qu'une unité de compte mondiale (un bankdollar) viendra mettre fin aux désordres de la spéculation sur les monnaies nationales. 